\title{
Desenvolvimento Econômico, Desigualdade e Saúde ${ }^{1}$
}

\author{
Economic Development, Inequality, and Health
}

\author{
Pedro Reginaldo Prata $^{2}$ \\ PRATA, P. R. Economic Development, Inequality, and Health. Cad. Saúde Públ., Rio de faneiro, 10 \\ (3): 387-391, ful/Sep, 1994.
}

\begin{abstract}
The author refers to the social, economic, individual, and collective dimensions of the relationship between health and disease. He considers that individuals and populations are not equally exposed to protective and risk factors. He highlights the uneven development between nations and Brazilian regions, and communities, as well as discussing the relationship between development, wealth, health, and social justice. The article analyzes development theories and makes a distinction between economic development and growth. The concepts of development trap and social refugees are coined. The author defines a healthy community, points to the need for a shift in the current development model, and delineates the health sector's role and limitations in dealing with social inequality.
\end{abstract}

Key words: Development; Inequality; Health Status; Public Health

\section{INTRODUÇÃO}

A saúde, a doença e a morte apresentam uma dimensão individual e coletiva (distribuída no espaço e no tempo). Não sendo um acontecer estritamente biológico também apresentam relação com fatores socioeconômicos, culturais, ambientais e subjetivos. Além disso indivíduos e grupos populacionais estão desigualmente submetidos a fatores protetores e de risco. Virchow, por exemplo, (mais conhecido no meio médico por sua obra: "Patologia Celular" de 1860) também escreveu sobre a desigualdade na distribuição e consumo, do que ele chamou de recursos sociais, como determinantes da saúde e doença, Waitzkin (1981).

Um interessante e dramático exemplo do determinante social da morte é encontrado no naufrágio do navio S. S. Titanic, no Atlântico Norte, na madrugada de 15 de abril de 1912: embora a tragédia da morte inesperada pareces-

\footnotetext{
${ }^{1}$ Trabalho apresentado na Conferência Internacional Sobre Meio Ambiente, Desenvolvimento e Saúde, Rio de Faneiro, Fundação Oswaldo Cruz.

${ }^{1}$ Departamento de Medicina Preventiva da Universidade Federal da Bahia. Rua Padre Feijó, 29, $4^{\circ}$ andar, Salvador, Bahia, 40113-170, Brasil.
}

se ser conseqüência de uma fatalidade inevitável e acidental, as chances de sobrevivência não foram iguais para todos os passageiros. $\mathrm{Na}$ primeira classe houve $62 \%$ de sobreviventes, na segunda $41 \%$ e na terceira somente $25 \%$.

Hall (1986) concluiu que os fatores relevantes para explicar o diferencial por classe foram: a localização dos botes salva-vidas no convés onde a primeira e a segunda classe se localizavam; uma política por parte da tripulação de cuidar, preferencialmente, dos passageiros da primeira e da segunda classe (negligenciando os da terceira que só encontraram o caminho para o convés dos botes salva-vidas por tentativa e erro) e finalmente, alguma exclusão (embora não-sistemática) por membros da tripulação, dos passageiros da terceira classe do convés onde estavam os botes salva-vidas.

$\mathrm{O}$ caso do Titanic exemplifica o que acontece com as populações em nossa sociedade: as pessoas são "escolhidas" para morrer por estarem submetidas a um risco diferencial de mortalidade, relacionado com as condições ambientais do lugar onde vivem, com suas condições de trabalho, o seu status socioeconômico, educacional e com a distribuição desigual dos recursos à que têm acesso. Portanto estão posicionadas com acesso desigual ao "bote salva-vidas do convés social". 
Este processo, silencioso, não é comumente percebido. Engels (1984: 61), por exemplo, ressaltou que:

"quando um individuo fere mortalmente alguém, o seu ato é chamado de assassinato; mas quando a sociedade coloca centenas de pessoas em tal situação que por não poderem sobreviver adequadamente, morrem prematuramente e ainda permite que estas condições assim permaneçam, isto também é assassinato. Entretanto ninguém pode ver o assassino porque a morte parece natural".

Ainda Engels (1973) utilizando-se de dados de Manchester (Inglaterra) concluiu que a taxa de mortalidade era inversamente relacionada com a classe social, não somente na cidade como um todo, mas também dentro de bairros específicos. Quase um século e meio depois Towsend \& Davidson (1982) também estudaram as desigualdades em saúde na Inglaterra e concluíram existir um diferencial de mortalidade relacionado com as classes sociais (em última instância, com as relações de produção).

Embora a organização da produção gere desigualdades, classe social pode ser considerada apenas uma dimensão da mortalidade desigual. Wood \& Carvalho (1988), por exemplo, chamam a atenção para o fato dos modos de produção econômica e de reprodução humana interagirem para determinar a estrutura demográfica da população (sua fertilidade, mortalidade e migração).

A estratificação social pode ser, portanto, identificada por outras dimensões além da classe social propriamente dita: pelas desigualdades resultantes do acesso diferenciado a recursos socioeconômicos, educacionais e ao poder político; pelas diferenças étnicas, religiosas e de sexualidade; pela exposição desigual a fatores ambientais e geográficos. Também, segundo Vaitsman (1992), como resultante de microrrelações de poder ao nível da família e instituições (escolas, serviços de saúde etc). A diversidade de uma dimensão coletiva: sóciocultural e de uma dimensão individual: genética, psíquica e subjetiva, complementam o quadro da desigualdade.

\section{DESENVOLVIMENTO, DESIGUALDADE ESAÚDE}

A economia política da saúde leva em consideração a existência de relações econômicas que criam desigualdades na renda, na riqueza e na saúde em particular. O conceito de desigualdade referencia a relação entre desenvolvimento e justiça social, estando relacionado com a distribuição de renda, educação, moradia, serviços (serviços de saúde, abastecimento de água e saneamento ambiental), acesso ao emprego, a bens de consumo, à terra, bem como ao poder de decisão e de influência social.

O desenvolvimento tem sido marcado por desigualdades históricas ao longo do tempo entre nações, entre regiões dentro de um mesmo país e entre grupos populacionais. Esta história tem sido também um processo durante o qual indivíduos, comunidades, grupos sociais interagem coletivamente com o objetivo de melhorar as suas condições de vida, procurando conseqüentemente sobrepor-se à injustiça e às disparidades, encontrando as suas próprias estratégias de sobrevivência.

A ênfase brasileira no crescimento econômico como o maior objetivo do desenvolvimento, levando a altos níveis de industrialização e urbanização, teve como resultado uma sociedade profundamente desigual, com uma grande distância entre os que possuem e os despossuídos, uma profunda desigualdade no desenvolvimento regional e na distribuição da renda e riqueza resultante deste crescimento.

Visto este quadro pelo ângulo otimista da teoria da modernização, as desigualdades sociais deveriam simplesmente diminuir depois de um período de transição para a modernidade, de tal forma que segundo Wood \& Carvalho (1988: 16):

"a pobreza crescente e persistente seria o custo necessário do estágio primeiro do desenvolvimento. A pobreza generalizada $e$ as disparidades entre uma elite afluente e o resto da população deveriam ser vistas como características inevitáveis, ainda que transitórias, do processo de desenvolvimento". 
Em contraste, a teoria da dependência econômica desenvolvida por Cardoso (1973), argumenta que o desenvolvimento quando dependente exacerba as desigualdades. O rápido desenvolvimento econômico não teria na América Latina, o mesmo resultado daquele encontrado nos países mais desenvolvidos, devido ao controle da economia Latino Americana pela introdução externa de tecnologias de capital intensivo. É também importante considerar que a revolução industrial na Europa se deu junto com a exploração colonial do mundo nãoEuropeu e que a concentração de capital no mundo industrializado levou, depois do colonialismo, ao imperialismo, quando as companhias multinacionais passaram a investir no exterior para expandir lucros e acumular poder político.

Entretanto, a concepção de um desenvolvimento relacionado com o atendimento de necessidades sociais básicas vem desviando a ênfase no crescimento econômico para o bemestar social. De acordo com Grosse \& Harkavy (1980) a imediata redistribuição de renda e recursos para combater a pobreza rural e urbana tornar-se-ia, neste caso, prioritária, já que como argumenta Seers (1969) se a pobreza, o desemprego e as desigualdade se agravam, seria incoerente chamar este resultado de desenvolvimento mesmo quando a renda per capita tenha dobrado.

No entanto, da mesma forma que a teoria da dependência econômica, esta concepção não considera os interesses enraizados das elites, das próprias nações em desenvolvimento, que se beneficiam do processo de modernização que, entretanto, sofre o impacto negativo deste modelo de desenvolvimento.

Além disso, atualmente, a dívida externa precisa ser também considerada como um mecanismo de dependência e de impedimento do desenvolvimento social. A título de exemplo vale mencionar que de acordo com o Banco Central, nos últimos dez anos (1983 a 1992) ingressaram no país aproximadamente U\$ 62 bilhões e foram desembolsados U\$ 130 bilhões. Apesar te terem sido pagos U $\$ 67$ milhões a mais do que foram recebidos, a dívida cresceu de U\$ 93 milhões para U $\$ 135$ bilhões de dólares.

Este processo leva a uma situação na qual a modernização por si mesma não é capaz de gerar bem-estar social e equidade, o que poderíamos chamar de armadilha do desenvolvimento. A prevista transição advogada pela teoria da modernização não resultaria, portanto, em justiça social sem mudanças no próprio modelo de desenvolvimento.

Esta desigualdade pode ser ilustrada pela magnitude do fluxo migratório ocorrido no Brasil. O êxodo rural seja para as fronteiras agrícolas ou para o industrializado Sudeste, correspondeu a 1,3 milhão de pessoas por ano durante os anos sessenta e a 1,7 milhão durante os anos 70 .

No Nordeste, por exemplo, deveu-se principalmente a fatores de estagnação econômica, de onde as pessoas migraram, geralmente para o Sudeste atraídas pelo processo de industrialização. Já no Sul, a partir dos anos 70, o fluxo migratório se deu principalmente para as novas fronteiras agrícolas da região Centro-Oeste e Norte, devendo-se não a fatores de estagnação, mas sim a fatores de mudança na estrutura da produção agrícola no Sul, resultando pela primeira vez, na região, um fluxo de agricultores sem terra para as novas fronteiras da região Amazônica (como Mato Grosso e Rondônia).

Esses refugiados sociais (graças a um desenvolvimento desigual, injusto e aético) migram por não terem como manter a sua subsistência. Adotam, portanto, uma estratégia de sobrevivência, embora deixem para trás importantes e estruturantes referências sócioculturais. Estes mais uma vez sofrerão riscos diferenciados e maiores de adoecer e morrer prematuramente.

A maioria dos que migram para o Sudeste apesar de estarem em uma região com melhor infra-estrutura de serviços, sofrem um risco diferenciado de adoecer por viverem, principalmente, em favelas e loteamentos periféricos, com precariedade ambiental e de serviços. Já na região Norte, tomando como exemplo o que ocorreu no pólo de desenvolvimento Grande Carajás (na região Amazônica de Tucuruí), estudos preliminares feitos por Prata \& Costa (1988) mostraram que além de um aumento da mortalidade no grupo etário com menos de cinco anos, houve também uma mudança no pico de mortalidade: do grupo etário com mais de 50 anos, para o grupo economicamente ativo (de 15 a 49 anos) onde ocorreram $82 \%$ das 
mortes. As principais causas de morte foram: doenças infecciosas e causas externas. A migração de populações suscetíveis, o desequilíbrio ecológico e violentos conflitos sociais parecem ter sido a principal razão para este novo padrão de mortalidade.

Assim o resultado dos chamados projetos de desenvolvimento e colonização tem sido uma rede de devastação e morte prematura. Wood \& Carvalho (1988) concluíram que para os agricultores pobres a esperança de um futuro promissor na Amazônia desapareceu, na medida em que a região reflete progressivamente as desigualdades que marcam o resto da sociedade brasileira. O impacto desta realidade na saúde da população é o resultado da forma como vem ocorrendo a ocupação humana nestas regiões.

Um indicador da persistente desigualdade qualitativa e quantitativa do desenvolvimento no Brasil pode ser encontrado no processo de transição epidemiológica diferenciada que vem-se dando no Brasil e suas regiões, conforme ilustrado por Prata (1992).

É importante ter em mente as implicações de todos estes fatores (históricos, políticos e econômicos) como determinantes das existentes desigualdades no bem-estar, na saúde e na mortalidade entre aqueles beneficiados pelo crescimento econômico e aqueles mantidos a sua margem.

\section{CONCLUSÃO}

A economia clássica deu ênfase ao papel da acumulação de capital no desenvolvimento econômico e pouca atenção aos aspectos humanos e sociais. Uma grande proporção da população que vive em regiões mais pobres ou em áreas pobres de regiões mais ricas, estão mais suscetíveis a doenças e a morte prematura. A concepção de que as doenças podem ser um entrave ao crescimento econômico, não leva em consideração que a pobreza é também o resultado de um desenvolvimento desigual.

A demografia clássica (neomalthusiana), por outro lado, procura identificar, unilateralmente, a pobreza como conseqüência do aumento populacional. Na verdade, a miséria está muito mais relacionada com a inequidade da distribuição da riqueza entre nações, regiões e grupos populacionais.
É interessante também ressaltar que é freqüente o debate sobre o papel das ações de saúde pública no declínio da mortalidade, em situações de subdesenvolvimento econômico. Quando não acompanhada pela queda da natalidade tem como conseqüência o aumento populacional, diminuindo a renda per capita e segundo King (1990), tornando a equidade ainda mais difícil de ser alcançada no futuro. Este problema, de forte conotação política e ética, traz para discussão a polêmica conclusão de que a melhoria nos coeficientes de mortalidade, em situação econômica adversa, pode resultar em mais subdesenvolvimento, piora da qualidade de vida e insustentabilidade social e ambiental.

Se a relação crucial entre pobreza, saúde e doença é estrutural, a questão fundamental, tendo-se em mente que cuidados médicos não significam necessariamente melhor estado de saúde, é saber o papel das políticas de saúde na erradicação da miséria socialmente induzida e tolerada, bem como de suas conseqüências.

Conforme salientou Mburu (1983), uma boa estratégia é a existência de programas integrados. Além disso, os serviços de saúde podem contribuir para atacar o ciclo pobreza-doençasofrimento, assumindo como sua responsabilidade específica a preocupação com os efeitos das doenças e suas conseqüências adversas (Blaxter, 1983).

Temos, como observaram Jong \& Rutten (1983), de um lado os meios e métodos para promover a saúde e de outro as desigualdades no desenvolvimento em geral e na saúde em particular. O objetivo, portanto, deve ser o de equalizar o quanto possível o estado de saúde da população, dando prioridade àqueles que mais necessitam, uma vez que como foi salientado anteriormente o crescimento econômico não é capaz de trazer bem-estar social por si só. É preciso levar em consideração quem de fato se beneficia do desenvolvimento. Grosse (1980: 165) constata:

"O crescimento da renda nacional é uma útil medida de potencial para o desenvolvimento. Não é por si mesmo desenvolvimento do potencial humano, também não há uma correspondência entre crescimento da renda e melhoria de condições de vida". 
É possível observar que se o amplo contexto da desigualdade na sociedade não é resolvido, a luta pela equidade na saúde se torna um processo isolado e interminável. Uma comunidade saudável seria, portanto, aquela que fosse capaz de identificar e entender os determinantes e condicionantes da desigualdade, da miséria, de um meio ambiente insalubre, das doenças e do sofrimento entre os seus membros; sendo também capaz de construir os meios de superação destes problemas, criando um desenvolvimento sustentável que dê suporte à uma vida saudável e digna.

\section{RESUMO}

PRATA, P. R. Desenvolvimento Econômico, Desigualdade e Saúde. Cad. Saúde Públ., Rio de Janeiro, 10 (3): 387-391, jul/set, 1994.

O autor se refere a dimensão socioeconômica, individual e coletiva do fenômeno saúde-doença. Refere-se também ao fato das populações estarem sobre a influência desigual de fatores de risco e de proteção à saúde. Discute as desigualdades no desenvolvimento e a relação entre desenvolvimento, riqueza, saúde e justiça social. Questiona as teorias de desenvolvimento econômico, diferenciando desenvolvimento de crescimento. Cunha os conceitos de armadilha do desenvolvimento e refugiados sociais. Define uma comunidade saudável. Propõe a necessidade de mudança no modelo de desenvolvimento. Baliza o papel e as limitações do setor saúde no que diz respeito a iniqüidade social.

Palavras-Chave: Desenvolvimento; Desigualdade; Saúde Coletiva; Nível de Saúde

\section{REFERÊNCIAS BIBLIOGRÁFICAS}

BLAXTER, M., 1983. Health services as a defence against poverty in industrialized societies. Social Science and Medicine, 17: 1139-1148.

CARDOSO, F. H., 1973. Associated dependent development: theorethical and practical implications. In: Authoritarian Brazil (A. Stepan, ed.), pp. 142-178, New Haven: Yale University Press.

ENGELS, F., 1973. The Conditions of the Working Class in England. Moscow: Progress Publishers.

ENGELS, F., 1984. Health. In: Health and Disease (N. Black; D. Boswell; A. Gray; S. Murphy \& J. Popay, eds.), pp. 61-65, Milton Keynes: Open University Press.

GROSSE, R. N., 1980. Interrrelation between health and population: observations derived from field experiences. Social Science and Medicine, 14C: 99-120.

GROSSE, R. N. \& HARKAVY,O., 1980. The role health in development. Social Science and Medicine, 14 C: 165-169.

HALL, W., 1986. Social class and survival on the S. S. Titanic. Social Science and Medicine, 22: 687-690.

JONG, G. A. \& RUTTEN, F. F. H., 1983. Justice and health for all. Social Science and Medicine, 17: 1085-1095.

KING, M., 1990. Health is a sustainable state. The Lancet, 336: 664-667.

MBURU, F. M., 1983. Health systems as defences against the consequences of poverty: equity in health and social justice. Social Science and Medicine, 17: 1149-1157.

PRATA, P. R., 1992. A transição epidemiológica no Brasil. Cadernos de Saúde Pública, 8: 168-175.

PRATA, P. R. \& COSTA, E. A., 1988. A Hidroelétrica de Tucuruí e seu Impacto no Perfil Epidemiológico. Relatório Técnico. Rio de Janeiro: Engevix. (Mimeo.)

SEERS, D., 1969. The meaning of development. International Development Review, 11: 01-07. TOWSEND, P. \& DAVIDSON, N., 1982. Inequalities in Health. Harmondsworth: Penguin Books.

VAITSMAN, J., 1992, Saúde cultura e necessidades. In: Saúde Coletiva? Questionando a Onipotência do Social (S. Fleury, org.), pp. 157-174, Rio de Janeiro: Relumé-Dumara.

WAITZKIN, H., 1981. The social origins of illness: a neglected history. International Fournal of Health Services, 11: 77-103.

WOOD, C. H. \& CARVALHO, J. A. M., 1988. The Demography of Inequality in Brazil. Cambridge: Cambridge University Press. 